\title{
PROTESTOS NO FEMININO NA EUROPA: DAS “MARIAS DA FONTE” ÀS MARCHAS MUNDIAIS DAS MULHERES
}

\author{
Célia Taborda SILVA \\ Professora Associada, Universidade Lusófona do Porto \\ celia.taborda@ulp.pt
}

\begin{abstract}
Resumo
As mulheres estiveram presentes nos protestos ao longo da época contemporânea, embora seja difícil até ao século XX discernir o papel concreto que tiveram nas revoltas ou contestação públicas. Alguns estudos revelaram que elas tiveram um papel ativo nos motins de subsistência dos finais do século XVIII e início de XIX na Europa. Muitas vezes, eram as mulheres que desencadeavam os motins, de forma espontânea, embora, quase sempre, fossem os homens que os finalizavam. Desta maneira também ocorreu na maior revolta popular que aconteceu em Portugal, em 1846, a "Maria da Fonte". No nome desta revolta estão personificadas todas as mulheres anónimas que ao longo da história tiveram coragem de se manifestar, fosse por uma questão de subsistência, religiosa, política ou social.

Nos anos 60 , do século XX, as feministas organizaram um conjunto de ações coletivas, que fugiam às tradicionais lutas de classes, muito ligadas ao movimento operário e ao marxismo. As mulheres atuavam em coletivos e juntavam-se a outras "minorias", como estudantes e negros, tinham preocupações culturais, identitárias, de género, daí as suas manifestações públicas terem sido integradas naquilo que os sociólogos denominaram de novos movimentos sociais. Como afirmou Touraine, os direitos culturais foram-se sobrepondo aos económicos, políticos e sociais, mas sem os eliminar (2006).

Os movimentos sociais feministas foram conseguindo algumas benesses sociais e políticas para as mulheres, ao mesmo tempo que sensibilizaram a opinião pública para a sua causa.

Atualmente, continuam a manifestar-se, como é exemplificativa a Marcha Mundial das Mulheres, que começou no ano 2000 , e que procura dar visibilidade às questões de género, sexualidade e diversidade.

Numa Europa que pugna pela igualdade e justiça social, as mulheres ainda buscam reconhecimento, como refere Fraser (2002), o que nos leva a pesquisar, neste artigo, as conquistas efetivas das mulheres através dos protestos públicos.
\end{abstract}

Palavras-chave: Mulheres, protestos, direitos, conquistas

\begin{abstract}
Women were present in the protests throughout the contemporary era, although it was difficult until the twentieth century to discern the concrete role they had in public revolts or contestation. Some studies have shown that they played an active role in the food riots of the late eighteenth and early nineteenth centuries in Europe. Often, it was the women who set off the riots, spontaneously, though, almost always, the men were finishing them. So also occurred in the greatest popular revolt that happened in Portugal, in 1846, the "Maria da Fonte". In the name of this revolt are embodied all the anonymous women who throughout history had the courage to manifest, whether for subsistence, religious, political or social.

In the 1960s, in the twentieth century, feminists organized a set of collective actions that ran away from traditional class struggles, closely linked to the workers' movement and Marxism. Women acted collectively and joined other "minorities" as students and blacks, had cultural, identity, gender concerns, hence their public manifestations were integrated into what sociologists have called new social movements. As Touraine argued, cultural rights overlapped with economic, political and social rights, but did not eliminate them (2006).

Feminist social movements have achieved some social and political benefits for women, while raising public awareness of their cause. The World March for Women, which began in the year 2000, continues to manifest itself as an example. It seeks to give visibility to issues of gender, sexuality and diversity.

In a Europe that struggles for equality and social justice, women still seek recognition, as Fraser (2001) points out, which leads us to research in this article the actual achievements of women through public protest.
\end{abstract}

Keywords: Women, protests, rights, achievements 


\section{Introdução}

A historiografia só começou a interessar-se por questões sociais, nomeadamente os movimentos sociais, nos quais se inserem os protestos femininos, no início do século $X X$, com a Escola dos Annales (BURKE, 1990). Até então, os estudos históricos incidiam sobre temáticas políticas, diplomáticas, institucionais, razão pela qual a história social e cultural, na qual se insere a história das mulheres, mais concretamente a dos protestos, só tem trabalhos de referência a partir dos anos 1960-70.

A História ao afastar-se do positivismo do século XIX, abriu espaço para o estudo das minorias coletivas, interessou-se pela história dos sem história, ou seja, as pessoas comuns, incluindo nas suas pesquisas a história das mulheres. A partir desse momento, estas passaram de uma categoria biológica a sujeitos que vivem e atuam no tempo. No entanto, a história das mulheres, enquanto objeto de estudo, é recente, foi impulsionada a partir de 1970, muito pela difusão do Feminismo. Assuntos relacionados com as mulheres, que durante muito tempo foram desconhecidos ou desvalorizados, chamaram a atenção dos historiadores, como é o caso dos protestos femininos.

Doravante uma "nova especialidade histórica nasceu contendo por objeto as mulheres, tornando-as sujeitos da história" (LOUISE TILLY, 1994: 34). A história das mulheres permitiu observar as mesmas nas suas relações sociais, económicas e políticas, bem como desconstruir as representações do papel feminino, que ditava que às mulheres cabiam as tarefas do lar e da procriação, construídas pelo discurso masculino.

As mulheres sempre foram atores da História, embora essa visibilidade só lhes foi reconhecida a partir do momento em que o seu papel começou a ser estudado. Como "sujeitos" históricos elas promoveram ou participaram em motins, revoltas, manifestações, marchas e greves ao longo do tempo, sobretudo nos séculos XIX e XX. Atualmente, continuam a manifestar-se da mesma forma, como revela o movimento de alterglobalização Marcha Mundial das Mulheres, e a despeito dos direitos que foram alcançando, ainda sentem falta de reconhecimento que vá além da justiça social, como refere Nancy Fraser (2002). Assim sendo, neste artigo, pretendemos analisar se os protestos só trouxeram visibilidade ou conquistas efetivas para as mulheres e qual a razão que as leva a utilizar, em pleno século XXI, o mesmo método reivindicativo, o protesto nas ruas, que utilizavam nos séculos passados, para alcançar reconhecimento.

\section{As mulheres nas revoltas}

Não é fácil aos historiadores discernirem o papel que as mulheres tiveram nas revoltas populares, pelo facto de que, na maioria dos casos, elas não apareciam diferenciadas na documentação. É comum na descrição de uma revolta referenciarem apenas os amotinados, sem fazer referência ao género. Mesmo em motins em que havia detenções e alguns dos sublevados se tornavam mais visíveis, a percentagem de mulheres que compareciam ante os tribunais era em muito menor número. De acordo com Edward Thompson isso acontecia, porque, muitas vezes, eram as mulheres que desencadeavam o motim, mas eram os homens que o terminavam. A iniciativa do 
levantamento era das mulheres, ao qual se juntavam os homens, que acabavam por ficar sozinhos no final da rebelião, principalmente quando apareciam as autoridades (THOMPSON, 1995 a: 360).

Alguns trabalhos têm revelado que as mulheres tiveram um papel ativo nas revoltas, nomeadamente nos motins de subsistência dos finais do século XVIII e XIX (LOGUE, 1979, THOMPSON, 1995). Segundo Edward Thompson o seu destaque aconteceu por serem elas mais sensíveis aos problemas relacionados com a falta de cereais, o preço exagerado dos mesmos ou as práticas abusivas por parte dos comerciantes. Em Newcastle, um grupo de mulheres, lideradas por uma tal Jane Bogey, tocaram os sinos a rebate e, revoltadas, cortaram a passagem aos cavalos que transportavam cereais (THOMPSON, 1995a). Em Birmingham, um grupo de «furiosas mulheres» apedrejaram um comerciante com as suas próprias batatas (THOMPSON, 1995).

Devido à sua maior sensibilidade quanto à inanição familiar, com frequência elas provocavam um motim espontâneo, que podia começar por uma gritaria em frente à tenda de um vendedor, ou o impedimento de carros de cereais de passarem por uma determinada urbe. A sua explosão devia-se a terem menos temor à lei, quer por ignorância, quer pelo privilégio do seu género (THOMPSON, 1995). $\mathrm{Na}$ altura, existia uma certa inculpabilização das mulheres, pois durante muito tempo foram consideradas inimputáveis.

As mulheres não participaram só em motins de subsistência. É hoje inquestionável a participação das mulheres na Revolução Francesa, não obstante, nessa época, a intervenção das mulheres no espaço público ser "rejeitada por praticamente todos os homens" (HUNT, 2009: 23). O seu papel era ocupar-se do espaço privado, encarregar-se de cuidar da casa, do marido e dos filhos, os assuntos relacionados à vida pública eram uma desonra. Como escreveu Rousseau a D' Alembert: "toda mulher em público que se mostra, se desonra" (PERROT, 2008: 136).

Malgrado a distinção rígida entre géneros seguida na sociedade francesa do século XVIII (PERROT, 2008:136), em Paris, algumas mulheres organizaram clubes femininos ou tornaram-se membros de sociedades populares (GODINEAU, 1984: 574). É claro que a sua ação "política" era menos organizada que a dos "sans-culottes" masculinos, por isso a sua palavra revolucionária era passada frequentemente nos mercados e ruas por onde costumavam andar. Desta forma, a sua organização era pouco estruturada, mas tinha a vantagem de ser mais dificilmente controlável e desmantelada (GODINEAU, 1984: 574). Foi, então, a partir das suas incipientes sociedades ou mesmo da rua que elas participaram massivamente nas lutas revolucionárias. Designadas por as "bota fogo", encontramos as mulheres à cabeça das principais insurreições parisienses. Na marcha sobre Versalhes, em 1789, foram as primeiras a avançarem. Nos levantamentos da Primavera de 1795 , foram elas que tocaram os sinos a rebate e fizeram rufar os tambores nas ruas da cidade. Utilizavam a sua criatividade, as formas pouco formais de atuação, os velhos ritos carnavalescos para zombarem das autoridades e darem corpo aos protestos. Ocupavam as ruas e incitavam os homens à ação. Mas apesar de todo este protagonismo, as mulheres foram excluídas das associações políticas, das assembleias e, a partir de maio de 1795 , foram proibidas de se juntarem na rua em número superior a cinco. A sociedade, dominada politicamente pelos homens, não podia permitir aqueles devaneios femininos por muito tempo. Terminada a revolução, as mulheres foram devolvidas ao «santuário doméstico» que Ihes estava reservado, dada a sua natureza «doce e frágil», tendo os 
clubes sido interditos, já que elas não deviam sair das suas famílias para se imiscuir em assuntos do governo (GODINEAU, 1984: 575). Após 1789, os governantes referiam que só foi permitido às mulheres participar na revolução para consolar e encorajar os companheiros na sua batalha patriótica.

Apesar dos silêncios das mulheres na História (PERROT, 2005:26), os seus protestos nas ruas mostram a ausência de passividade feminina. Algumas, ainda que um pequeno grupo, oriundas da baixa burguesia, interessaram-se pela política e pelos direitos femininos. As mulheres que tiveram um papel relevante durante a revolução francesa sentiram-se excluídas dos direitos propagados na mesma revolução. A Declaração dos Direitos do Homem e do Cidadão (1789) dizia que todos os homens nasciam livres e iguais, dotados de razão, com exceção das mulheres. É certo que nem todos os homens estavam aqui incluídos, apenas os instruídos ou possuidores de bens, mas as mulheres estavam totalmente excluídas. O contrato social de Rousseau não contemplava as mulheres como sujeitos de direitos políticos, relegava-as para o espaço privado, limitando-as à sua função reprodutora. Tanto este filósofo iluminista, como outros, expuseram uma visão muito doméstica do papel da mulher. Condorcet foi dos poucos que defendeu a igualdade entre homens e mulheres. Neste cenário, foram as próprias mulheres que defenderam os seus direitos, mesmo arriscando a vida, como fez Olympe de Gouges (1748-1793). Esta adepta das ideias de Condorcet reivindicou a participação pública das mulheres, na Assembleia, nos salões e nas ruas. Em 1791, escreveu a Declaração dos Direitos da Mulher e da Cidadã, onde afirmou a igualdade de nascimento da mulher face ao homem. O seu posicionamento político acabou por levá-la à morte, foi guilhotinada em 1793, sob acusação de contra revolucionária.

Durante a primeira metade do século XIX, na europa ocidental, foi através dos motins nas ruas que as mulheres mostraram a sua força, principalmente nos meios rurais, como aconteceu em Portugal, em 1846, na revolta da "Maria da Fonte".

\subsection{A revolta das mulheres portuguesas, a "Maria da Fonte"}

A História das mulheres em Portugal também enferma dos mesmos problemas da historiografia europeia, falta de informações "concretas e circunstanciadas" (VAQUINHAS, 2004: 150). A exclusão das mulheres do poder, das instituições, do direito, juntamente com uma interiorização dos valores masculinos por parte das mesmas, tornou-as praticamente invisíveis. A mulher assumiu um papel social de inferioridade e subordinação sustentado em narrativas masculinas. Em nome de uma moral defensora da virtude e do silêncio feminino (PERROT, 1998), aceitaram ou consentiram a dominação dos homens.

Toda esta moral de recato, pudor e de recolhimento dos olhares externos aplicava-se muito mais à mulher aristocrata ou burguesa do que à camponesa. Esta última tinha maior liberdade de comportamento, de palavras, de gestos, de atitudes (VAQUINHAS, 2004: 152), por causa disso apareceram frequentemente em levantamentos ou motins populares, sobretudo em motins de 
subsistência, tal como na Europa (NETO, 1996). Por esta razão não é de estranhar que tivessem desencadeado a maior revolta popular da História portuguesa, a "Maria da Fonte".

Esta revolta aconteceu em pleno período de implantação do liberalismo, época de grandes mudanças estruturais tendentes à modernização do país. O liberalismo foi difícil de implementar no Portugal rural que existia no século XIX (SILVA, 2007). A legislação liberal suscitou muita reação por parte dos povos, particularmente nas regiões mais afastadas da capital, como o Minho, motivo pelo qual, em 1846, foi palco da grande revolta camponesa em oposição à legislação do ministro Costa Cabral.

Em 1842, António Bernardo da Costa Cabral, conquistou o poder, e de imediato tomou uma série de medidas tendentes à reestruturação da Administração e Finanças, com vista ao progresso do país. O descontentamento popular não tardou a manifestar-se. As reformas mais polémicas, contudo, foram as tributárias e as da saúde. Em 19 de abril de 1845, foi publicado o diploma sobre as contribuições diretas de repartição, que operava uma profunda transformação no sistema fiscal, substituindo uma série de impostos por três tributos: predial, de maneio e pessoal. A lei foi posta em execução a 16 de fevereiro de 1846, sendo de imediato contestada (Silva, 2015). Para o povo, como refere Oliveira Martins (s/d), o imposto era considerado a "ladroeira» dos homens de Lisboa. Os camponeses começaram a desconfiar dos empregados do Estado que Ihes batiam à porta para inquirir dos seus bens e a entrarem em confronto com eles. A contribuir para o desagrado sobreveio a execução das Leis de Saúde, que decretava a obrigatoriedade dos enterramentos nos cemitérios, e o imposto do covato, provocando uma transformação das atitudes relativas às práticas ligadas à morte e aos enterros. Por tudo isto, não foi com indiferença que as populações rurais viram ruir o Portugal antigo, para elas o verdadeiro, o ditoso, o bom, mais uma vez, nas palavras de Oliveira Martins (s/d), substituído por um novo e desconhecido Portugal (OLIVEIRA MARTINS, s/d).

A "Maria da Fonte", como o nome faz alusão, foi uma revolta de mulheres. Mulheres do povo do Minho. Os primeiros motins da "Maria da Fonte", começaram na Póvoa de Lanhoso, distrito de Braga, entre 19 e 24 de março, na freguesia de Fonte Arcada, quando um grupo de mulheres impediu o pároco da freguesia de sepultar um cadáver fora da Igreja, no cemitério local, fazendo-o elas mesmas dentro do templo (CAPELA E BORRALHEIRO, 1996). Foi uma revolta tipicamente rural, logo não visava a mudança mas a perpetuação do costume. Segundo Charles Tilly (1976), as revoltas rurais são, em regra, sempre defensivas, reativas a algo que desestabilize a ordem tradicional rural e viole os direitos locais. Nesta revolta do Minho, a reação prendeu-se com aspetos soteriológicos, na alteração dos seus hábitos religiosos, crenças e mesmo de afetividade para com os seus parentes falecidos. A sepultura nos cemitérios era um sacrilégio para a mentalidade popular da época, sobretudo a feminina, a mais ligada aos rituais fúnebres. Desobedecendo às leis do Estado, estas "Marias", amotinaram-se e fizeram frente ao pároco e aos guardas e, apesar da sua coragem, não visavam nada de novo, apenas preservar os seus costumes.

Existem várias teorias acerca da designação deste movimento, houve uma mulher a liderar o motim ou foi o grupo? Desde a literatura à historiografia todos procuraram uma heroína, alguns destacaram mesmo algumas figuras femininas da época, mas nenhuma das versões aventadas convenceu. A versão mais aceite é que o movimento foi coletivo, foi uma ação de heroínas, mulheres 
que enfrentaram o poder pelas suas conviç̧ões. Os motins de abril e maio de 1846, ao começaram em Fonte Arcada, pensa-se, deram o nome ao movimento, fazendo alusão a esse facto o nome da freguesia "Fonte". "Maria" representava todas as mulheres, pois no Minho a mulher tinha um papel relevante na família e na economia da casa, era um pilar para a sobrevivência familiar (DURÃES, 2002: 142). Destarte, a individualidade do nome remete para a ousadia feminina, razão para ter permanecido na memória coletiva como um símbolo da coragem e determinação das mulheres. $\mathrm{O}$ nome desta revolta é simbólico, invoca a ação coletiva feminina, não de uma, mas de todas as mulheres que destemidamente ou inconscientemente ousaram enfrentar o poder do Estado.

Nas cidades, o papel da mulher portuguesa não foi tão destacado como no meio rural, ficando secundarizada face ao Homem nos protestos. Porém, foi nos meios urbanos europeus que surgiu o feminismo e as mulheres afirmaram a sua cidadania.

\subsection{Os protestos femininos urbanos oitocentistas}

Nas cidades portuguesas, também houve "Marias da Fonte", especialmente no final da segunda metade do século XIX, época de industrialização e progresso do país. A estabilização política que se seguiu a 1851 permitiu que se dotasse Portugal de infraestruturas que facilitaram o desenvolvimento industrial, e com ele o surgimento do movimento operário, à semelhança do que há muito vinha a acontecer na Europa. As duras condições de vida do operariado levou-os a manifestações e greves, as mulheres também participaram, embora em muito menor número e raramente identificadas (SILVA, 2016: 126). O trabalho nas fábricas era duro para os homens, mas para as mulheres era quase insustentável. A existência destas mulheres era extremamente fatigante. Cuidavam da casa, dos maridos e dos filhos e trabalhavam à volta de 12 horas por dia. Algumas ainda tinham de andar quilómetros, descalças, para chegar ao local de trabalho. Na fábrica dedicavam-se a um trabalho árduo e monótono, que não admitia enganos e se se enganavam, descontavam-Ihes no ordenado; se se distraíam, podiam ficar sem os dedos. Eram doze horas no meio de um frio gélido no Inverno ou de um calor sufocante no Verão, mas sempre no meio da poeira. Os homens viam-nas como causa do desemprego masculino e desrespeitavam-nas e os capatazes eram intolerantes. Inseridas num meio tão adverso desde a meninice, tornavam-se rudes, brutas e zaragateiras, algumas acabavam por enveredar pelo caminho da prostituição (SILVA, 2016: 119). Alguns jornais evidenciaram a exploração feminina, pela voz das próprias mulheres, escreveu uma delas: "A vós companheiras de trabalho e de infortúnio, me dirijo; a vós que sofreis como eu a dupla escravidão do capital e do homem. Algumas de nós abraçámos o belo ideal libertário, porque compreendemos que só com a ampla liberdade que ele preconiza a humanidade poderá ser feliz. Todos os homens, quer proletários, quer burgueses, e todas as classes dominantes têm conservado sempre a mulher na maior ignorância para mais facilmente a poderem dominar" (COSTA, 2013: 14). Este artigo assinado por uma mulher evidencia laivos de feminismo no seio do movimento operário português, ecoando as ideias feministas que circulavam pela europa. As mulheres portuguesas tinham motivos para protestar nas ruas e fizeram-no, embora conjuntamente com os homens, as suas 
reivindicações foram sobretudo salariais e laborais: melhores salários, redução das horas de trabalho, melhores condições de trabalho. A questão da cidadania política ou direito ao voto pouco se colocava, uma vez que os homens ainda não haviam conquistado esse direito (CRUZ, 1996: 250).

Pelo contrário, no restante espaço urbano europeu, durante o século XIX, a ação coletiva feminina esteve muito ligada às reivindicações de direitos políticos, como o direito ao voto. Muitas mulheres participaram no movimento operário e as sufragistas fizeram diversas manifestações e ações públicas para conseguirem obter direitos fundamentais. Os protestos das sufragistas atingiram grandes proporções: ocupação de ruas, passeatas, comícios, greves de fome, o que levou a agressões e distúrbios públicos. Muitas sufragistas foram presas, destacando-se, nesta luta, Emmelyne Pankhurst. Esta mulher, nascida em 1858, foi uma ativista dos direitos das mulheres e fundadora da União Social e Política das Mulheres. Provenientes da aristocracia, burguesia e classe trabalhadora, as mulheres lutaram toda a segunda metade do século XIX pelos seus direitos, inclusive chegaram a morrer por aquilo em que acreditavam. Foi o caso de Emily Davison, que morreu, em 1913, quando se atirou para a frente do cavalo do rei, na famosa corrida de cavalos, em Derby.

Esta primeira "onda" de contestação feminina tinha por base questões de cidadania política e também direitos básicos como educação, propriedade e melhor remuneração. Segundo Eisler "o trabalho de centenas de feministas do século XIX melhorou e muito a situação do contingente feminino da humanidade" (Eisler, 2007: 218). Contudo, só no final de um período de muito protesto e por alterações no contexto histórico, no início do século $\mathrm{XX}$, as reivindicações das mulheres tiveram expressão política.

\section{Os protestos das "Marias" no século XX: dos N.M.S aos movimentos globais}

As Guerras do século XX, ao mobilizarem os homens para lutar, abriram o espaço público para as mulheres e, embora esse espaço estivesse muito condicionado ao esforço de guerra, permitiu que "a categoria "mulher", que esteve até o século XX numa situação de exclusão sócio-económica e inferioridade na escala de prestígio social" (GOHN, 2007: 45), se afirmasse.

As guerras trouxeram alterações políticas e sociais, que se manifestaram no pós-guerra pela emergência de um conjunto de movimentos sociais: estudantis, pacifistas, étnicos, feministas, com cariz mais identitário e cultural, são os designados de Novos Movimentos Sociais (N.M.S). Para alguns dos teóricos dos Novos Movimentos Sociais (TOURAINE, 1998, HABERMAS, 1986, MELUCCI, 1996) os protestos verificados na década de sessenta do século XX, são o reflexo de uma nova classe média (HABERMAS, 1986, OFFE, 1985), menos preocupada com questões materialistas ou sociais elementares e mais focada em questões universalistas como a paz, o meio ambiente ou o género. A era dourada do capitalismo permitiu que mais indivíduos tivessem acesso a um bem-estar económico, fazendo emergir uma classe média escolarizada, qualificada, muito ligada a funções públicas (OFFE, 1985) e cujos protestos já não resultam da industrialização mas da pós- 
industrialização, em que os conflitos deixam de girar à volta do capital-trabalho e se centram em quesitos culturais e informacionais. Todavia, a estes novos protestos juntaram-se os atores dos velhos protestos (OFFE, 1985).

Os anos sessenta ficaram marcados por grande contestação social. Nos Estados Unidos, mais precisamente na Califórnia, surgiu o movimento hippie, contra a guerra do Vietname, e com a proposta de um novo modo de vida que contrariava os valores de consumo e morais da época. O seu lema era "paz e amor". Os negros americanos lutavam pela igualdade racial liderados por Marther Luther King. As colónias europeias procuravam a autodeterminação. Na Europa, aconteceu o "Maio de 68", em Paris, quando os estudantes ocuparam a Sorbonne, pondo em causa a ordem acadêmica estabelecida há séculos, em busca de novas formas culturais. Em Portugal, vivia-se a ditadura do Estado Novo, o que não impediu alguma contestação, inclusive feminina. Mesmo com o discurso de domesticidade do regime, nos meios urbanos, a "oposição das mulheres ao regime fazia-se sentir em torno das lutas nos locais de trabalho centradas nas questões salariais, na defesa do emprego, do horário de trabalho de oito horas e na melhoria das condições de trabalho" (TAVARES, 2008: 94). E, não obstante, as restrições legais que impediam a autonomia e emancipação das mulheres, houve algumas manifestações, mormente universitárias, em que participaram.

No meio desta efervescência contestatária há uma "erupção dos feminismos" (OFFEN, 2008), embora com cadências distintas nos países europeus. Na década de sessenta, as mulheres fundaram movimentos de libertação inspiradas em feministas, como Betty Fridan e a sua obra "Mística Feminina", que intervinham socialmente em busca de maior liberdade e igualdade. A medicina deu uma ajuda com o surgimento da pílula anticoncecional, que revolucionou os costumes e deu à mulher uma ousadia sexual, até então inexistente.

Essa década terminou com as mulheres nas ruas a protestar. No final de 1968, um ajuntamento de mulheres, cerca de 400 ativistas do movimento Women's liberation, tentou impedir o concurso Miss América, em Atlantic City. Tencionavam fazer uma fogueira para queimar sutiãs e outros apetrechos femininos (DUFFET, 1968). Apesar de terem sido impedidas de protestar pelas autoridades, o episódio que ficou conhecido como a "queima de sutiãs" estendeu-se à Europa, onde realmente houve fogueiras. Em 1970, fizeram uma greve, em Nova lorque, que trouxe 50 mil pessoas para as ruas. Estas manifestações de feministas, o compartilhar experiências comuns, refletir sobre a condição feminina e o papel das mulheres na sociedade forjou uma identidade coletiva (MELUCCI, 1989, 2001) e a partir daí o seu reconhecimento como atores sociais.

Segundo Iris Marion Young, as várias correntes do feminismo afirmaram o Feminismo como o "movimento de política cultural de mais alcance" (YOUNG, 2000:150), tornando-se, assim, um dos grandes movimentos do século XX.

No final do século, na Europa e Estados Unidos, o movimento feminista conseguiu que algumas das reivindicações das mulheres fossem ouvidas e atendidas pelos setores da sociedade política e civil. Discussões em volta de temas como a sexualidade, a contraceção e o aborto, foramse dissipando à medida que se tornavam conquistas legais. As mulheres conseguiram afirmar a identidade feminina e a partir de então repensaram o modelo de atuação no espaço público, 
buscaram a internacionalização e o reconhecimento e o movimento feminista tentou ganhar dimensão à escala global. Foi neste contexto que surgiu o movimento Marcha Mundial das Mulheres (MMM).

A Marcha Mundial das Mulheres insere-se nos movimentos à escala global. Agregou vários movimentos internacionais. A marcha é uma das formas de ação coletiva, a par das manifestações, petições, greves, e já tinha sido usada, ao longo da História (DEBOUZY, 2003, PIGENET e TARTAKOWSKY, 2003) como forma de reivindicação. Esta Marcha, sendo de grande dimensão, pretendia projetar o movimento através da divulgação que teria nos meios de comunicação social e desta forma chamar a atenção para a sua causa. Como refere Sherer-Werren a finalidade era "produzir visibilidade através da mídia e efeitos simbólicos para os próprios manifestantes (no sentido político-pedagógico) e para a sociedade em geral, como uma forma de pressão política das mais expressivas no espaço público contemporâneo" (2006: 112).

A inspiração para a criação da Marcha Mundial das Mulheres partiu de uma manifestação realizada em 1995, no Canadá, quando 850 mulheres marcharam 200 quilômetros, entre Quebec e Montreal, pedindo, simbolicamente, "Pão e Rosas". No final desta ação, diversas conquistas foram alcançadas, como o aumento do salário mínimo, mais direitos para as mulheres imigrantes e apoio à economia solidária.

A Marcha Mundial das Mulheres não foi uma mobilização pontual, tornou-se numa plataforma de ação de caráter mais permanente, definida como uma rede feminista mundial, que começou no dia 8 de março de 2000 e se repetiu em 2005 e 2010. As marchas têm uma carga simbólica e, na maioria das vezes, as datas em que ocorrem não são escolhidas por acaso (DEBOUZY, 2003: 22). É o caso do 8 de março, Dia Internacional da Mulher.

O lema da marcha de 2000 foi a luta contra a violência e pobreza. Teve ações em mais de 150 países, envolvendo mais de 6000 grupos de mulheres (TAVARES, BENTO, MAGALHÃES, 2004: 11). No final da marcha, estes grupos participantes, redigiram um documento com dezassete pontos de reivindicações para ser entregue à O.N.U. Este movimento aspirava a que os governos tomassem medidas concretas contra a pobreza e violência sobre as mulheres. As ações, deste ano, terminaram a 17 de outubro, com uma manifestação em Nova lorque.

Em 8 de março de 2005, o movimento MMM realizou marchas por todo o mundo onde estiveram presentes nas ruas milhares de mulheres. A marcha era pela Solidariedade e Diversidade, e tinha por objetivo a mudança política e social. No final elaboraram a Carta Mundial das Mulheres para a Humanidade. Nesse documento são exaltados os valores da igualdade, liberdade, justiça, paz e solidariedade entre os Povos. Entre 8 de março e 17 de outubro foi proposto a cada país que elaborasse um retalho em forma de quadrado para a confeção de uma colcha, aludindo às propostas da Carta, mas com especificidades culturais de cada país participante, donde resultou uma colchamosaico de solidariedade (PINGRET, 2012: 11).

Entre 8 e 18 de março de 2010, ocorreram várias marchas pelo mundo para assinalar o centenário do Dia Internacional da Mulher. As ações de 2010, tinham como slogan "seguiremos em marcha até que todas sejamos livres". Os eventos deste ano encerraram em Bukavu, na República Democrática do Congo, cidade onde as mulheres se confrontavam diariamente com o conflito armado. As integrantes da Marcha justificaram a escolha: 
"Exercer pressão política sobre governos e instituições políticas multilaterais (por exemplo, ONU) para que efetuem as mudanças necessárias para melhorar as condições e a qualidade de vida das mulheres do mundo, incluindo uma política de desarmamento e de resolução pacífica dos conflitos, o fim de toda impunidade, da corrupção, da utilização do estupro como arma de guerra, das ocupações e da presença militar estrangeira, bem como a imposição de embargos políticos e econômicos" (documento 5 da $3^{a}$ ação da MMM).

O movimento MMM chamava a atenção da O.N.U que Tratados e Convenções só faziam sentido quando fossem reais para todas as Mulheres. A globalização, ainda evidenciou mais as desigualdades sociais e mostrou que "as mudanças tecnológicas, laborais, culturais, políticas e sociais dos últimos quarenta anos provocaram rupturas mas reforçaram continuidades na opressão, subordinação e exploração das mulheres" (TAVARES, BENTO, MAGALHÃES, 2004: 3). Deste modo, justificava-se o recurso à marcha, uma "arma" que sempre foi eficaz nos protestos públicos, para chamar a atenção para uma causa.

Este movimento também se expressa, como tantos outros de feministas, nos Fóruns Sociais Mundiais. Em 2003, no Fórum de Porto Alegre, as feministas da MMM organizaram um painel inserido na temática "Direitos Humanos" (TAVARES, BENTO, MAGALHÃES, 2004: 10), podendo, desta forma, ter uma participação mais ativa. Em Portugal, a UMAR integra esta rede e, como tal, teve um papel significativo nas Marchas organizadas pela MMM. Estes movimentos de alterglobalização, ao mundializarem a resistência feminina, contribuem para o empoderamento das mulheres.

\section{Conclusão}

Ao longo do tempo, as mulheres foram tomando consciência de si como sujeitos históricos. A subordinação social a que estiveram votadas, perpetuada por hábitos e costumes ancestrais, colocou-as numa posição de desvantagem e injustiça (YOUNG, 1990). Este processo de consciencialização foi redefinindo o papel das mulheres em termos sociais e políticos.

As ações de protesto tiveram um papel crucial neste caminho, ao permitir-Ihes sair da esfera privada da domesticidade e reprodução a que tinham sido relegadas pela superioridade e dominação masculina (OKIN, 2008: 308). Os motins populares foram a expressão mais visível das primeiras manifestações das mulheres na esfera pública, da sua presença fora de casa e da influência que tiveram junto da comunidade. As revoluções liberais do século XIX deixaram as mulheres sair às ruas, abrir clubes revolucionários, mas também as souberam fazer regressar aos lares sem sequer Ihes reconhecerem mais privilégios. Mesmo os filósofos das luzes, que reconheciam os direitos universais, deixaram de fora as mulheres, já que esses direitos era para quem usava a razão e as mulheres eram consideradas sentimentais, vinculadas ao mundo das emoções, daí terem-lhes rapidamente retirado protagonismo. Foi só no século XX, muito por ação do movimento feminista, que algumas das reivindicações das mulheres se tornaram direitos adquiridos. Os movimentos sociais feministas foram alcançando benesses sociais e políticas, ao mesmo tempo que sensibilizaram a 
opinião pública para a sua causa. No início do século XXI, os protestos femininos ganharam projeção e visibilidade mundial com a comunicação de massas e as redes sociais e os movimentos feministas passaram a atuar em redes de movimentos globais, como é o caso do movimento MMM. Desta forma pretendem o empoderamento de todas as mulheres no mundo, pois as conquistas das mulheres europeias ainda não são uma realidade global. O movimento MMM mostrou que a atuação em Fóruns e Congressos não tinha resultados práticos para o reconhecimento de todas as mulheres, pois os abusos, o preconceito, a violência, os silêncios, ainda existem, logo a utilização da Marcha. As marchas sempre foram usadas como ação privilegiada nos movimentos de contestação, porque não implicam envolvimento político ou ideológico (DEBOUZY, 2003: 66-68), provavelmente, a escolha desta forma de protesto terá que ver com a autonomia institucional e política que o movimento quis dar a esta marcha pela diversidade, pluralidade e solidariedade. Apesar de a marcha não visar conotações institucionais ou políticas, esta almejava conseguir mudanças políticas para todas as mulheres.

\section{Bibliografia}

BURKE, P. (1990). La revolucion historiografica francesa. La escuela de los Annales: 1929-1989. Barcelona: Gedisa, 1990.

CAPELA, J., VIRIATO, BORRALHEIRO, R. (1996). A Maria da Fonte na Póvoa de Lanhoso. Póvoa de Lanhoso: Câmara Municipal.

COSTA, A.A. (2013). O Germinal, um roteiro acrata para a revolução social. In Atas do I Congresso de História do Movimento Operário e dos Movimentos Sociais em Portugal (pp.8-24),vol. I. Lisboa: FCSH-UN.

CRUZ, M. A. (1996). Direito de voto no tempo da Maria da Fonte. In Atas do Congresso Maria da Fonte (pp.249-263). Póvoa de Lanhoso: Câmara Municipal.

DEBOUZY, M. (2003). Les marches de protestation aux États-Unis ( XIXe - XXe siècles). In Le Mouvement Social, n²02 (1), 15-41.

DUFFET, J. (1968). WLM vs. Miss America. Voice of the Women's Liberation Moviment, 4.

DURÃES, M. (2002). Qualidade de vida e sobrevivência económica da família camponesa minhota: o papel das herdeiras (secs XVIII-XIX). Cadernos Noroeste, vol.17 (1-2), 125-144.

EISLER, R. (2007). O cálice e a espada: nossa história, nosso futuro. Rio de Janeiro: Rocco.Editora.

FRASER, N. (2002). A justiça social na globalização: redistribuição, reconhecimento e participação. Revista Crítica de Ciências Sociais, outubro, 7-20.

GODINEAU, D. (1984). Vision de la participation politique des femmes à la Révolution française (1793 - An III). In Mouvements Populaires et Conscience Sociale, XVI-XIX siècles. Paris: Maloine.

HABERMAS, J. (1986). The Theory of Communicative Action. The Critique of Functionalist Reason, vol. 2. Cambridge: Polity Press. 
HUNT, L. (2009). Revolução francesa e vida privada. In Philippe Ariés \& George DUBY(Org.). História da vida privada. São Paulo: Companhia das Letras, 2009.

LOGUE, K. J.(1979). Popular disturbances in Scotland, 1780-1815. Edimburgo.

MELLUCCI, A. (1989). Um objetivo para os movimentos sociais? Revista Lua Nova, n 17, 49-66.

MELUCCI, A. (1996). Challenging Codes. Collective Action in the Information Age. Cambridge, Cambridge University Press.

MELLUCCI, A. (2001). A invenção do presente: movimentos sociais nas sociedades complexas. Petrópolis: Vozes.

NETO, M. S. (1996). Motins populares na Gândara em 1778. In Atas do Congresso Maria da Fonte (pp.249-263). Póvoa de Lanhoso: Câmara Municipal.

OFFE, C. (1985). New social movements: challenging the boundaries of institutional Politics. Social Research, 52 (4), 817-868.

OKIN, S. (2008). Gênero, o público e o privado. Estudos Feministas, Florianópolis, 16(2): 305-332.

OLIVEIRA MARTINS (s/d). Portugal Contemporâneo. Lisboa: Europa-América, $2^{\circ} \mathrm{vol}$.

PERROT, M. (2005). As mulheres ou os silêncios da História. São Paulo: EDUSC.

PERROT, M. (2009) (Org.). História da vida privada 4: Da Revolução Francesa à Primeira Guerra. São Paulo: Companhia das Letras.

PIGENET, M., Tartakowsky, D. (2003). Les marches en France aux XIXe et XXe siècles : récurrence et métamorphose d'une démonstration collective. Le mouvement Social, n²02 (1), 69-94.

PINGRET, A. (2012). A composição visual da marcha mundial das mulheres (Brasil, 2000-2010). Domínios da imagem, ano V, n. 10, 7-22.

SCHERER-WERREN, I. (2006). Das mobilizações às redes de movimentos sociais. Sociedade e Estado, v. 21, n. 1, 109-130.

SILVA, C. T. (2007). Movimentos sociais no Douro no período de implantação do liberalismo (18341855). Porto: Gehvid.

SILVA, C.T (2015). Ação colectiva no Douro oitocentista: a propósito da "Maria da Fonte". Atas das 3as Conferências do Museu de Lamego (pp.47-59). Lamego: Museu de Lamego/Citcem.

SILVA, C.T (2016). Conflitualidade operária no Porto Oitocentista. In António Simões do Paço; Cátia Teixeira; Paula Godinho; Raquel Varela; Virgílio Borges (coord.). In Atas do I Congresso de História do Movimento Operário e dos Movimentos Sociais em Portugal (pp.117-128). Lisboa: FCSH-UN

THOMPSON, E. (1995 a). La Economía Moral Revisada. In Costumbres en Común. Barcelona: Crítica.

THOMPSON, E. (1995). La Economía «Moral» de la Multitud en la Inglaterra del siglo XVIII. In Costumbres en Común. Barcelona: Crítica.

TILLY, C (1976). The Vendée. $3^{\mathrm{a} e d . ~ M a s s a c h u s e t t s: ~ H a r v a r d ~ U n i v e r s i t y ~ P r e s s . ~}$

TILLY, L.A (1994). Gênero, História das Mulheres e História Social. Cadernos Pagu (3), 29-62.

TOURAINE, A. (1998). Pourrons-Nous Vivre Ensemble? Paris, Editions Fayard. 
VAQUINHAS, I. (2004). As mulheres na sociedade portuguesa oitocentista. Algumas questões económicas e sociais (1850-1900). In Benedita Duque Vieira (org.), Grupos sociais e estratificação social em Portugal no século XIX (pp.149-164.). Lisboa: CEHCP.

YOUNG, I.M. (2000). La Justicia y la Politica de la diferencia. Madrid: Ediciones Cátedra.

OFFEN, K.(2008). Erupções e fluxos: reflexões sobre a escrita de uma história comparada dos feminismos europeus, 1750-1950. In Anne Cova (dir.), História Comparada das Mulheres (pp.29-45). Lisboa: Livros Horizonte.

GOHN, M.G. (2007). Mulheres - atrizes dos movimentos sociais: relações político-culturais e debate teórico no processo democrático. Política \&Sociedade, n 11, outubro, 41-70.

TAVARES, M., BENTO, A., MAGALHÃES, M.J. (2004). Feminismos e Movimentos Sociais em tempos de Globalização: o caso da MMM. In VIII Congresso Luso-Afro-Brasileiro de Ciências Sociais, (pp.1-17). Coimbra: CES.

TAVARES, M. (2008). Feminismos em Portugal (1947-2007). Tese de Doutoramento em Estudos sobre as Mulheres, Especialidade em História das Mulheres e do Género. Lisboa.Universidade Aberta. 